\title{
Evaluation of Hydraulic Parameters Obtained by Different Measurement Methods for Heterogeneous Gravel Soil
}

\author{
Chen Zeng ${ }^{1,2}$, Quanjiu Wang ${ }^{3,4, *}$, and Fan Zhang ${ }^{1,2}$ \\ ${ }^{1}$ Key Laboratory of Tibetan Environment Changes and Land Surface Processes, Institute of \\ Tibetan Plateau Research, Chinese Academy of Sciences, Beijing, China \\ ${ }^{2}$ Muztagh Ata Westerly Observation and Research Station, Institute of Tibetan Plateau Research, \\ Chinese Academy of Sciences, Beijing, China \\ ${ }^{3}$ State Key Laboratory of Soil Erosion and Dryland Farming on the Loess Plateau, Institute of \\ Soil and Water Conservation, Chinese Academy of Sciences, Yangling, China \\ ${ }^{4}$ Institute of Water Resources, Xi'an University of Technology, Xi'an, China
}

Received 12 September 2011, accepted 22 May 2012

\begin{abstract}
Knowledge of soil hydraulic parameters for the van Genuchten function is important to characterize soil water movement for watershed management. Accurate and rapid prediction of soil water flow in heterogeneous gravel soil has become a hot topic in recent years. However, it is difficult to precisely estimate hydraulic parameters in a heterogeneous soil with rock fragments. In this study, the HYDRUS-2D numerical model was used to evaluate hydraulic parameters for heterogeneous gravel soil that was irregularly embedded with rock fragments in a grape production base. The centrifugal method (CM), tensiometer method (TM) and inverse solution method (ISM) were compared for various parameters in the van Genuchten function. The soil core method (SCM), disc infiltration method (DIM) and inverse solution method (ISM) were also investigated for measuring saturated hydraulic conductivity. Simulation with the DIM approach revealed a problem of overestimating soil water infiltration whereas simulation with the SCM approach revealed a problem of underestimating water movement as compared to actual field observation. The ISM approach produced the best simulation result even though this approach slightly overestimated soil moisture by ignoring the impact of rock fragments. This study provides useful information on the overall evaluation of soil hydraulic parameters attained with different measurement methods for simulating soil water movement and distribution in heterogeneous gravel soil.
\end{abstract}

Key words: Soil hydraulic parameter, van Genuchten function, Model inverse solution, HYDRUS 2D

Citation: Zeng, C., Q. Wang, and F. Zhang, 2012: Evaluation of hydraulic parameters obtained by different measurement methods for heterogeneous gravel soil. Terr. Atmos. Ocean. Sci., 23, 585-596, doi: 10.3319/TAO.2012.05.22.03(WMH)

\section{INTRODUCTION}

The Richards equation, a foundation of the physicsbased models, was derived from the principle of the conservation of mass and Darcy's law (Lei et al. 1988) which can be extended to more complex conditions (Brunone et al. 2003; Pachepsky et al. 2003; Elmaloglou and Diamantopoulos 2008). Numerical models of the Richards soilwater kinetic equation are an efficient tool that can be used to describe variable saturated soil water flow such as rainfall infiltration and runoff, subsurface recharge, migration of nutrients, solution transport, and design and monitoring

\footnotetext{
* Corresponding author

E-mail:wquanjiu@163.com
}

of irrigation and drainage systems (Bagarello et al. 2005). Unsaturated hydraulic conductivity $K(\theta)$, soil water diffusivity $D(\theta)$ and specific water capacity $C(\theta)$ as functions of water content $\theta$ are necessarily basal parameters which help understand soil water movement laws and quantitatively analyze soil water movement with mathematical modeling method. These three parameters are almost impossible to measure directly. Hence, soil water characteristic curves are proposed to indirectly solve this problem based on $K(\theta)$ $=D(\theta) \times C(\theta)$. Among the models fitting characteristic curves, van Genuchten model, describing the moisture absorption processes, was considered to be the most popular to fit soil water characteristics. Therefore, parameters of van 
Genuchten function, $\alpha, n, \theta_{r}$ and $\theta_{s}$, as well as saturated hydraulic conductivity $(K s)$ needed to calculate $K(\theta)$, become a key for solving the Richards equation.

Soil water characteristic curves can be produced using different methods (Lei et al. 1988). Each has its pros and cons. (1) The tensiometer method can obtain successive measurement of soil water potential and be easily applied in the field; however, this method has a limited measurement range and the results can be affected by soil spatial variability. (2) The pressure membrane method has a wide measurement range of soil potential, but is time consuming. (3) The tension table method is easy to operate and is low-cost, but is limited to a narrow measurement range. (4) The centrifugal method can save time, but error is easily incorporated during the centrifugal process through heating and compacting soil sample. The compaction effect is more profound for a loamy soil than a sandy soil (Reeve et al. 1980).

Different techniques have been applied for measuring $K$. They include the constant head-cutting ring method (Klute and DirKsen 1986), the Guelph permeameter method (Reynolds and Elrick 1985; Elrick and Reynolds 1992; Xu and Mermoud 2003), the single-ring infiltrometer method (van Es et al. 1999; Bagarello and Sgroi 2004), the doublering infiltrometer method (Starr 1990), and the inversed-auger-hole method (Messing and Jarvis 1990). In recent years, tension infiltromenters have been widely used for measuring the near-saturated $K$ (Perroux and White 1988) in the field to investigate the spatial and temporal variability of soil hydraulic properties (Das Gupta et al. 2006; Hu et al. 2009). This method was considered to be water saving, repeatable and stable in space and time (Ventrella et al. 2005; Bagarello and Sgroi 2007).

Owing to the soil forming process and human activities, certain rock fragments or gravel layers are usually embedded in soil. The rock fragments can be ignored when their content is not high and has little influence on soil water movement. However, a large portion of rock fragments should be taken into account (EriKsson 1996). In general, the content of rock fragments can be investigated with four methods, including the cutting ring sampling method (Flint and Childs 1984), the digging method (Muller and Hamilton 1992), the probe method (Viro 1952), and the ray/radio wave method (Fleming et al. 1993; Rey et al. 2006). All of these methods are time and energy consuming and difficult to obtain satisfactory results in a heterogeneous medium. In addition, although the impact of size, content and distribution of rock fragments on soil water movement have been studied by many scholars, conflicting trends often exist in various reports revealing positive correlations, negative correlations, no correlations or a "turning point" between the size/content and infiltration ability (conduction) (Mehuys et al. 1975; Bouwer and Rice 1984; Ravina and Magier 1984; Brakensiek et al. 1986; Sauer and Logsdon 2002; Khaleel and Heller 2003). Consequently, it has been a challenge to understand the impact of rock fragments on soil hydraulic character, especially at a heterogeneous research site. Predicting soil water flow and distribution accurately and rapidly in heterogeneous gravel soil becomes a hotspot in recent years (Ma et al. 2009, 2010).

Numerical simulations are efficient tools to study soil water movement in various complex conditions (Lubana and Narda 2001; Gärdenäs et al. 2005). Researchers have been attempting to study the effect of rock fragments via the "black-box" model in complex conditions. Many simulation software packages have been developed in recent years, including HYDRUS-2D (Šimůnek et al. 1999), a well-known Windows-based computer software package used for simulation on water, heat and solute movement in a $2 \mathrm{D}$ variably saturated porous media (Cote et al. 2003; Skaggs et al. 2004). Based on a finite element method, the HYDRUS-2D was developed to solve the Richards's equation, and was proved to be in good agreement for observed and simulated data (Ben-Gal et al. 2004; Skaggs et al. 2004; Provenzano 2007).

The objective of this study was to evaluate soil hydraulic parameters by using the HYDRUS-2D to compare various methods. The parameters $\alpha, n, \theta_{r}$ and $\theta_{s}$ were measured using the centrifugal method and the tensiometer method, and the parameter $K s$ was measured using the soil core method and the disc infiltration method, respectively.

\section{MATERIALS AND METHODS}

\subsection{Study Site Description}

The field research was conducted in a grape cultivated base, located in the eastern part of Shanshan county (425'소 $90^{\circ} 30^{\prime} \mathrm{E}, 416 \mathrm{~m}$ elevation), Xinjiang Uygur Autonomous Region, China. The climate was characterized as arid, with mean annual precipitation of $25.3 \mathrm{~mm}$ and potential evaporation of $2751 \mathrm{~mm}$. The mean annual temperature was $14^{\circ} \mathrm{C}$. Ground water table was $70 \mathrm{~m}$ depth below the surface. The soil had a deeper layer of Gobi gravel soil originating from Gobi gravel, and was covered by a layer of exotic sandy loam soil heterogeneously mixed with rock fragments in the top $50 \mathrm{~cm}$. Soil particle sizes collected at the depths of $0-5$ and $60-65 \mathrm{~cm}$ were determined using a MasterSizer 2000 laser particle size analyzer (Malvern, UK). These two soil layers had the texture of sandy loam soil (SI standard) (Table 1). The proportion of rock fragment in each soil layer was measured using the gravimetric method. Because the rock fragments were heterogeneously distributed in profiles, the rock fragment contents shown in Table 2 were the average values of the $0-50 \mathrm{~cm}$ upper layer and the $50-120 \mathrm{~cm}$ layer (Table 2). Thompsons Seedless grapes were planted in 1980. The cultivation inter-row space was $3.5 \mathrm{~m}$, which included a $0.9-1.2 \mathrm{~m}$ wide furrow part and a $2.3-2.6 \mathrm{~m}$ wide ridge part within each row. The surface of cultivated furrow was treated as a reference level 
Table 1 . Soil particle size distribution at 0 - 5 and $60-65 \mathrm{~cm}$ layers for the study site.

\begin{tabular}{c|c|c|c|c}
\hline \multirow{2}{*}{ Depth } & \multicolumn{3}{|c|}{ Particle size (\%) } & \multirow{2}{*}{ Texture } \\
\cline { 2 - 4 } & $<\mathbf{0 . 0 0 2} \mathbf{~ m m}$ & $\mathbf{0 . 0 0 2} \mathbf{- 0 . 0 2} \mathbf{~ m m}$ & $>\mathbf{0 . 0 2} \mathbf{- 1} \mathbf{~ m m}$ & \\
\hline $0-5 \mathrm{~cm}$ & 8.4 & 22.2 & 69.4 & Sandy loam \\
$60-65 \mathrm{~cm}$ & 4.8 & 24.6 & 70.6 & Sandy loam \\
\hline
\end{tabular}

Table 2. The gravimetric percentage of gravel content in each soil layer.

\begin{tabular}{|c|c|c|c|c|c|}
\hline \multirow{2}{*}{ Depth } & \multicolumn{5}{|c|}{ Gravel size $(\%)$} \\
\hline & $>50 \mathrm{~mm}$ & 20 - $50 \mathrm{~mm}$ & 10 - $20 \mathrm{~mm}$ & $2-10 \mathrm{~mm}$ & $\leq 2 \mathrm{~mm}^{a}$ \\
\hline $0-50 \mathrm{~cm}$ & 0.0 & 7.2 & 13.6 & 25.0 & 54.2 \\
\hline $50-120 \mathrm{~cm}$ & 7.6 & 19.3 & 16.8 & 22.0 & 34.3 \\
\hline
\end{tabular}

${ }^{a}$ The size less than and equal to $2 \mathrm{~mm}$ is defined as soil particle and the size greater than $2 \mathrm{~mm}$ is defined as stone according to soil particle definition.

of $0 \mathrm{~m}$. The ridge was about $40-50 \mathrm{~cm}$ higher than the furrow (Fig. 1). The study site was drip irrigated during the study period. Three drip irrigation tapes were laid along the cultivated furrow: (1) at the bottom of furrow, (2) on the ridge and near the grapevine root, and (3) on the ridge, about $50 \mathrm{~cm}$ apart from the second as shown in Fig. 1. Water movement below each individual dripper is usually considered as a point source infiltration process (Chu 1994). Hence, water transfer under drip irrigation can be assumed to be a 2D infiltration process with multi-point source provided that soil was horizontally uniform along the furrow direction. The drip irrigation flow for each emitter was $3.3 \mathrm{~L} \mathrm{~h}^{-1}$ with $30 \mathrm{~cm}$ spacing, and the irrigation quota through all three tapes was $525 \mathrm{~m}^{3} \mathrm{ha}^{-1}$ in each irrigation event.

\subsection{Sampling, Measurement and Parameterization}

\subsubsection{Measurement of $\alpha, \mathrm{n}, \boldsymbol{\theta}_{r}$ and $\boldsymbol{\theta}_{s}$, Hydraulic Param- eters of van Genuchten Function}

The van Genuchten function was selected as the soil water characteristic curve (van Genuchten et al. 1980) as follows

$$
\begin{aligned}
& \theta(h)= \begin{cases}\theta_{r}+\frac{\theta_{s}-\theta_{r}}{\left(1+|\alpha h|^{n}\right)^{m}} & h<0 \\
\theta_{s} & h \geq 0\end{cases} \\
& K(h)=K s S_{e}^{l}\left[1-\left(1-S_{e}^{\left.\frac{1}{m}\right)^{m}}\right]^{2}\right.
\end{aligned}
$$

where $\theta_{s}$ is the saturated volumetric water content $\left(\mathrm{cm}^{3} \mathrm{~cm}^{-3}\right)$; $\theta_{r}$ is the residual volumetric water content $\left(\mathrm{cm}^{3} \mathrm{~cm}^{-3}\right), h$ is the soil water pressure head $(\mathrm{cm}), \alpha$ is a parameter related to air-entry suction $\left(\mathrm{cm}^{-1}\right), m$ and $n$ are coefficients related to shape coefficient with a relation of $m=1-1 / n$ and $n>1$,
$K(h)$ is hydraulic conductivity $\left(\mathrm{cm} \mathrm{min}^{-1}\right), S_{e}$ is the effective water content, $l$ is a pore-connectivity parameter which is often assumed to be about 0.5 , an average value of many soils (Mualem 1976).

In this study, the hydraulic parameters of van Genuchten function, $\alpha, n, \theta_{r}$ and $\theta_{s}$, were obtained using two methods: the soil water characteristic function method (SWCFM) and the inverse solution method (ISM).

For SWCFM, soil water characteristic function was obtained by a centrifugal method (CM) and tensiometer method (TM). For CM, 9 undisturbed soil cores were taken from the depths of $0-5$ and $60-65 \mathrm{~cm}$ using a cutting ring ( $5 \mathrm{~cm}$ in height $200 \mathrm{~cm}^{3}$ in volume) in 2008 . Soil water potentials were measured using a thermostatic high-speed centrifuge (HITACHI, Japan). For TM, soil water potentials were manually measured using 9 tensiometers $(2500 \mathrm{~S}$, France). For the top soil layer, 9 tensiometers were buried at a shallow depth of $20 \mathrm{~cm}$ in 2009. For the deep soil layer, 9 tensiometers were buried at a depth of $60-65 \mathrm{~cm}$ in 2008 . Soil moisture around the tensiometers was synchronously measured using Time Domain Reflectometry (TDR) method (TRIME, German). The hydraulic parameters were obtained by fitting the soil water retention curves using RETC V6.02 software (van Genuchten et al. 1991).

For ISM, the initial soil water distribution in a vertical cross section along the whole $3.5 \mathrm{~m}$ inter-row horizontal width was measured using 5 neutron tubes at the depth of $20-120 \mathrm{~cm}$ with $20 \mathrm{~cm}$ intervals (503BD, China) (see Fig. 1) prior to the irrigation event. Soil water in the cultivated furrow surface and cultivated ridge was measured using the gravimetric method. After an irrigation event, a $3.5 \mathrm{~m}$ wide and $1.5 \mathrm{~m}$ deep vertical cross-section along the whole inter-row horizontal width was collected to measure soil water content by using the gravimetric method. These experiments were conducted from 2009 - 2010. The 


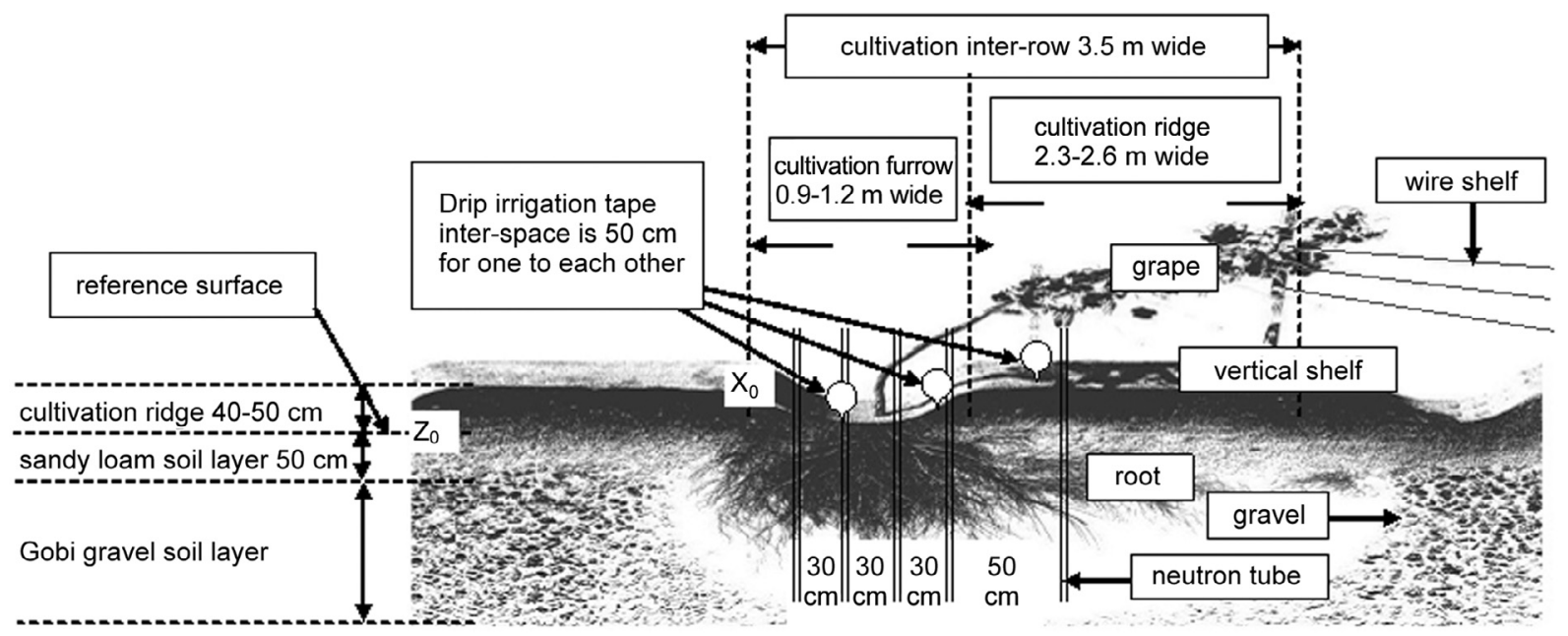

Fig. 1. The schematic diagram of the study site.

hydraulic parameters were obtained by the inverse solution of soil water distribution using the HYDRUS-2D V2.1 model.

\subsubsection{Measurement of $K s$}

In this study, $K s$ values were measured using three methods, the soil core method (SCM) (Klute and DirKsen 1986), disc infiltration method (DIM) (Logsdon and Jaynes 1993), and inverse solution method (ISM).

For SCM, Ks was obtained according to Darcy's law. The undisturbed soil core was sampled using a cutting ring as described in 2.2.1 and a Marriote bottle to keep a stable hydraulic head of $4.0 \mathrm{~cm}$. The discharge water volume $Q\left(\mathrm{~cm}^{3}\right)$ was recorded every $30 \mathrm{~min}$. Ks was calculated using stabilized $Q$ that was an average of the last three values until the differences were within the 5\% range for individual 30 min intervals. Then, $K s$ in $\mathrm{cm} \mathrm{min}^{-1}$ was calculated using Eq. (3):

$K s=\frac{Q L}{A T H}$

where $A$ is the cross sectional area of the soil core $\left(\mathrm{cm}^{2}\right), T$ is the time ( $\mathrm{min}), H$ is the hydraulic head $(\mathrm{cm})$, and $L$ is the length $(\mathrm{cm})$ of soil core.

For DIM, the configuration of disc infiltrometer was similar to that described by Ankeny et al. (1988) including an infiltrometer base with a radius of $7.5 \mathrm{~cm}$ and a reservoir tube with a radius of $1.7 \mathrm{~cm}$. The disc infiltrometer was used to determine infiltration under pressure heads of $-15,-6,-3$ and $0 \mathrm{~cm}$ in an ascending sequence. Before each measurement, the flat and cleared soil surface was prepared using a knife; and, a fine layer of sand (about $1 \mathrm{~mm}$ ) was evenly placed on the surface to ensure good contact between the infiltrometer base and the soil. For each infiltration mea- surement, the cumulative infiltration was recorded at $5 \mathrm{~min}$ intervals until steady infiltration occurred. After the first infiltration experiment finished, the following measurements with different pressure heads were repeated at the same location to reduce the spatial variability. The multi-tensions with a non-linear regression method as reported by Logsdon and Jaynes was believed to produce more stable results than other methods (Logsdon and Jaynes 1993) and hence was chosen in our study. The fitting equation is expressed as

$$
\frac{Q_{x}\left(h_{f}\right)}{\pi R^{2}}=K s \exp \left(\alpha_{0} h\right)+\frac{\left[4 K s \exp \left(\alpha_{0} h\right)\right]}{\pi R \alpha_{0}}
$$

where $Q_{x}\left(h_{f}\right)$ is the steady infiltration rate $\left(\mathrm{cm}^{3} \mathrm{~min}^{-1}\right)$ under pressure head of $h_{f}(\mathrm{~cm}), R$ is the radius of the disc infiltrometer $(\mathrm{cm}), \alpha_{0}$ is the Gardner constant that characterizes soil pore size distribution $\left(\mathrm{cm}^{-1}\right)$.

For the disc infiltrometer

$Q_{x}\left(h_{f}\right)=\frac{\pi r^{2} H_{0}}{t}$

where $r$ is the radius of the reservoir tube $(\mathrm{cm}), H_{0}(\mathrm{~cm})$ is the height of water drop in reservoir tube at time interval of $t$ (min).

Consequently, $K s$ can be calculated by combining Eqs. (4) and (5).

For ISM, $K s$ was obtained the same way as other hydraulic parameters using the HYDRUS-2D model as described in 2.2.1.

\subsection{Model Description}

The HYDRUS-2D model is based on the two-dimensional Richards equation. The program can be used to nu- 
merically solve the Richards equation for variably saturated water movement for a given soil, and has been used to simulate soil water movement by many researchers (Cote et al. 2003; Skaggs et al. 2004). The root uptake and evapotranspiration were not taken into account in this study. The water movement equation is described as

$$
\frac{\partial \theta}{\partial t}=\frac{\partial}{\partial x}\left[K(h) \frac{\partial h}{\partial x}\right]+\frac{\partial}{\partial z}\left[K(h) \frac{\partial h}{\partial z}+K(h)\right]
$$

where $\theta$ is the volumetric water content, $h$ is the soil water pressure head, $t$ is the time, $x$ is the horizontal coordinate with the origin at ridge-furrow interface beyond grape vine $\left(\mathrm{X}_{0}\right.$, see Fig. 1$), z$ is the vertical coordinate with the origin at the soil surface (positive upward) $\left(\mathrm{Z}_{0}\right.$, see Fig. 1$), K(h)$ is the unsaturated hydraulic conductivity.

The simulation zone (Fig. 2) with $3.5 \mathrm{~m}$ width, $2.0 \mathrm{~m}$ height for the furrow part and $2.5 \mathrm{~m}$ for the ridge part (a positive value represents above reference surface and a negative value stands for below the surface). The simulation zone was set for two soil types (above $50 \mathrm{~cm}$ and below $50 \mathrm{~cm}$ depth), then the finite element meshes of simulation zone were constructed by dividing the flow region into irregular triangular elements.

For the present study, both the initial condition and the upper boundary condition were

$h(x, z, 0)=h_{i}(x, z)$

$h(0,0, t)=h_{0}$

where $h_{i}(x, z)$ is the initial soil water pressure head, and $h_{0}$ is the soil water potential at soil surface. These values were set according to observed results. The upper boundary condition of infiltration points under the dripper was set as constant flux. The free drainage was considered as a lower boundary condition.

In our study, the simulation conditions were the same for different hydraulic parameters. The simulation time was set to $900 \mathrm{~min}$ in accordance with field sampling experiment. The HYDRUS-2D program was performed with 5 hydraulic parameters of $\alpha, n, \theta_{r}, \theta_{s}$ and $K s$ by 5 treatments: (1): CM-SCM; (2): CM-DIM; (3): TM-SCM; (4) TM-DIM; (5): ISM. An additional filed irrigation experiment was conducted to evaluate the accuracy of simulation results with the observed data obtained with different methods.

\subsection{Method of Analysis}

Analysis of variance (ANOVA) and Post Hoc Tests (using a least significant difference test when equal variance occurred and Tamhane's T2 when equal variance did

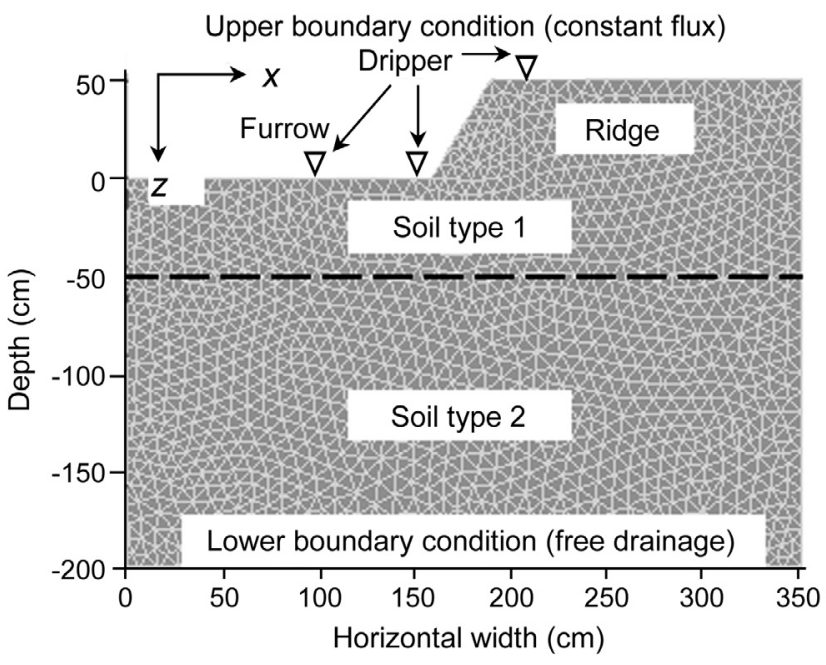

Fig. 2. The schematic diagram of the simulation zone.

not occur) were performed to analyze the difference of hydraulic parameters obtained with different methods. Paired $\mathrm{T}$ test was employed to compare the hydraulic parameters of the layers of $0-50 \mathrm{~cm}$ and below $50 \mathrm{~cm}$. The coefficient of variation $(\mathrm{CV})$ was used to evaluate the magnitude of soil water variability. Heterogeneity was considered weak if CV $<10 \%$, moderate if $10 \% \leq \mathrm{CV} \leq 100 \%$, and strong if $\mathrm{CV}>$ $100 \%$. These analyses were performed using SPSS V13.0 software.

The root mean square error (RMSE) was calculated to provide a quantitative comparison of the goodness-of-fit for the measured and simulated data, which can be expressed as

$\mathrm{RMSE}=\sqrt{\frac{1}{N} \sum_{i=1}^{N}\left(P_{i}-O_{i}\right)^{2}}$

where $N$ is the total number of observations, $O_{i}$ and $P_{i}$ are the observed and predicted values, respectively.

\section{RESULTS}

\subsection{Hydraulic Parameters of van Genuchten Function}

Table 3 shows the typical values of the hydraulic parameters for various soils given by the manual for the HYDRUS-2D program (Šimůnek et al. 1999), where $\alpha$ takes the mean values of $0.008,0.016,0.036$ and $0.145 \mathrm{~cm}^{-1}$, for clay, silt, loam and sand soil, respectively; $n$ takes the mean values of $1.09,1.37,1.56$ and 2.68 , for clay, silt, loam and sand soil, respectively; $\theta_{r}$ takes the mean values of 0.068 , $0.034,0.078$ and $0.045 \mathrm{~cm}^{3} \mathrm{~cm}^{-3}$, for clay, silt, loam and sand soil, respectively; $\theta_{s}$ takes the mean values of $0.38,0.46$, 0.43 and $0.43 \mathrm{~cm}^{3} \mathrm{~cm}^{-3}$ for clay, silt, loam and sand soil, respectively. Table 4 summarizes the statistical parameters 
of the hydraulic data sets obtained from the van Genuchten function with different methods.

In this study, Table 4 shows that, in the top $0-50 \mathrm{~cm}$, the average values of $\alpha$ for CM $>$ ISM $>$ TM. Moderate variation for $\mathrm{CM}(\mathrm{CV}=14.0 \%), \mathrm{TM}(\mathrm{CV}=11.7 \%)$ and weak variation for ISM $(\mathrm{CV}=3.6 \%)$ were observed. The average values of $n$ for TM $>$ ISM $>$ CM. Moderate variation for $\mathrm{CM}(\mathrm{CV}=15.1 \%)$ and $\mathrm{TM}(\mathrm{CV}=11.5 \%)$ and weak

Table 3. The typical values of soil hydraulic parameters for the van Genuchten function.

\begin{tabular}{lccccc}
\hline Soil type & $\boldsymbol{\theta}_{\boldsymbol{r}}$ & $\boldsymbol{\theta}_{\boldsymbol{s}}$ & $\boldsymbol{\alpha}$ & $\boldsymbol{n}$ & $\boldsymbol{K s}$ \\
\hline silt clay & 0.070 & 0.36 & 0.005 & 1.09 & 0.0003 \\
sandy clay & 0.100 & 0.38 & 0.027 & 1.23 & 0.0020 \\
clay & 0.068 & 0.38 & 0.008 & 1.09 & 0.0033 \\
silt & 0.034 & 0.46 & 0.016 & 1.37 & 0.0042 \\
clay loam & 0.095 & 0.41 & 0.019 & 1.31 & 0.0043 \\
silt loam & 0.067 & 0.45 & 0.020 & 1.41 & 0.0075 \\
loam & 0.078 & 0.43 & 0.036 & 1.56 & 0.0173 \\
sandy loam & 0.065 & 0.41 & 0.075 & 1.89 & 0.0737 \\
loam sand & 0.057 & 0.41 & 0.124 & 2.28 & 0.2432 \\
sand & 0.045 & 0.43 & 0.145 & 2.68 & 0.4950 \\
\hline
\end{tabular}

Table 4. Statistical summary of hydraulic parameters of the van Genuchten function obtained by different methods.

\begin{tabular}{|c|c|c|c|c|c|c|c|c|c|c|}
\hline \multirow{2}{*}{ Source } & \multicolumn{4}{|c|}{0 - $50 \mathrm{~cm}$ soil layer } & \multicolumn{4}{|c|}{ Below $50 \mathrm{~cm}$ soil layer } & \multicolumn{2}{|c|}{ Between two layers } \\
\hline & Min & Max & Mean & CV\% & Min & Max & Mean & CV\% & $\boldsymbol{F}$ & Sig. \\
\hline \multicolumn{11}{|l|}{$\alpha$} \\
\hline $\mathrm{CM}$ & 0.0523 & 0.0766 & 0.0614 & 14.0 & 0.0509 & 0.0808 & 0.0642 & 16.1 & 0.4074 & 0.5323 \\
\hline $\mathrm{TM}$ & 0.0212 & 0.0303 & 0.0256 & 11.7 & 0.0544 & 0.1023 & 0.0781 & 22.0 & 81.3092 & 0.0000 \\
\hline ISM & 0.0555 & 0.0594 & 0.0579 & 3.6 & 0.0761 & 0.0817 & 0.0788 & 3.6 & 107.8141 & 0.0005 \\
\hline \multicolumn{11}{|l|}{$n$} \\
\hline $\mathrm{CM}$ & 1.5787 & 2.4026 & 1.9380 & 15.1 & 1.9635 & 2.4856 & 2.2187 & 9.1 & 5.6354 & 0.0305 \\
\hline $\mathrm{TM}$ & 3.6625 & 5.0617 & 4.2979 & 11.5 & 2.1526 & 6.8571 & 4.4984 & 4.0 & 0.1046 & 0.7506 \\
\hline ISM & 2.1482 & 2.3293 & 2.2355 & 4.1 & 2.3577 & 2.5668 & 2.4476 & 4.4 & 6.8142 & 0.0594 \\
\hline $\mathrm{CM}$ & 0.0284 & 0.0411 & 0.0365 & 12.4 & 0.0298 & 0.0412 & 0.0369 & 11.5 & 0.0264 & 0.8731 \\
\hline $\mathrm{TM}$ & 0.0820 & 0.1123 & 0.1003 & 9.9 & 0.0473 & 0.1044 & 0.0794 & 22.9 & 9.1794 & 0.0080 \\
\hline ISM & 0.0332 & 0.0370 & 0.0349 & 5.7 & 0.0305 & 0.0315 & 0.0311 & 1.7 & 10.5008 & 0.0317 \\
\hline $\mathrm{CM}$ & 0.2782 & 0.3247 & 0.2993 & 5.5 & 0.1741 & 0.2243 & 02002 & 5.9 & 0.0106 & 0.9192 \\
\hline $\mathrm{TM}$ & 0.2535 & 0.3609 & 0.3187 & 9.8 & 0.1679 & 0.2170 & 0.1946 & 5.6 & 4.2098 & 0.0569 \\
\hline ISM & 0.3064 & 0.3256 & 0.3185 & 3.3 & 0.1862 & 0.2031 & 0.1940 & 2.9 & 9.8284 & 0.0350 \\
\hline \multicolumn{11}{|l|}{$K s$} \\
\hline SCM & 0.0823 & 0.1751 & 0.1261 & 24.7 & 0.0995 & 0.1803 & 0.1398 & 19.5 & 0.8584 & 0.3679 \\
\hline DIM & 0.2105 & 0.3882 & 0.3128 & 17.5 & 0.3291 & 1.5791 & 0.8722 & 38.0 & 24.8517 & 0.0001 \\
\hline ISM & 0.1993 & 0.2090 & 0.2029 & 2.6 & 0.5096 & 0.5456 & 0.5273 & 3.4 & 738.7692 & 0.0000 \\
\hline
\end{tabular}

Note: CM: centrifugal method; TM: tensiometer method; ISM: inverse solution method; SCM: soil core method; DIM: disc infiltrometer method. 
variation for ISM $(\mathrm{CV}=4.1 \%)$ were observed. The average values of $\theta_{r}$ for TM $>\mathrm{CM}>\mathrm{ISM}$. Moderate variation for $\mathrm{CM}(\mathrm{CV}=12.4 \%)$ and weak variation for $(\mathrm{CV}=9.9 \%) \mathrm{TM}$ and ISM $(\mathrm{CV}=3.6 \%)$ were observed. The average values of $\theta_{s}$ for $\mathrm{TM}>\mathrm{ISM}>\mathrm{CM}$. All the three measurement methods showed weak variation (with CV of 5.5\%, 9.8\% and 3.3\% for CM, TM and ISM, respectively).

Below $50 \mathrm{~cm}$, the average values of $\alpha$ for ISM $>$ TM $>\mathrm{CM}$. Moderate variation for $\mathrm{CM}(\mathrm{CV}=16.1 \%), \mathrm{TM}(\mathrm{CV}$ $=22.0 \%)$ and weak variation for ISM $(\mathrm{CV}=3.6 \%)$ were observed. The average values of $n$ for TM $>$ ISM $>$ CM. All the three measurement methods showed weak variation (with CV of $9.1 \%, 4.0 \%$ and $4.4 \%$ for CM, TM and ISM, respectively). The average values of $\theta_{r}$ for $\mathrm{TM}>\mathrm{CM}$
$>$ ISM. Moderate variation for CM $(\mathrm{CV}=11.5 \%), \mathrm{TM}(\mathrm{CV}$ $=22.9 \%)$ and weak variation for ISM $(\mathrm{CV}=1.7 \%)$ were observed. The average values of $\theta_{s}$ for CM > TM > ISM. All the three measurement methods showed weak variation (with CV of 5.9\%, 5.6\% and 2.9\% for CM, TM and ISM, respectively).

One-way ANOVA was performed to explore possible impacts of measurement methods on the hydraulic parameters in van Genuchten function. Figures 3 and 4 show the averaged parameters $\alpha, n, \theta_{r}$ and $\theta_{s}$ for various methods. Visually, some differences in $\alpha, n, \theta_{r}$ and $\theta_{s}$ existed among various methods. ANOVA analysis showed statistically significant difference for $\alpha, n, \theta_{r}(\mathrm{P}<0.001)$ in $0-50 \mathrm{~cm}$ depth and for $n$ and $\theta_{r}(\mathrm{P}<0.002)$ below the $50 \mathrm{~cm}$ depth. Results

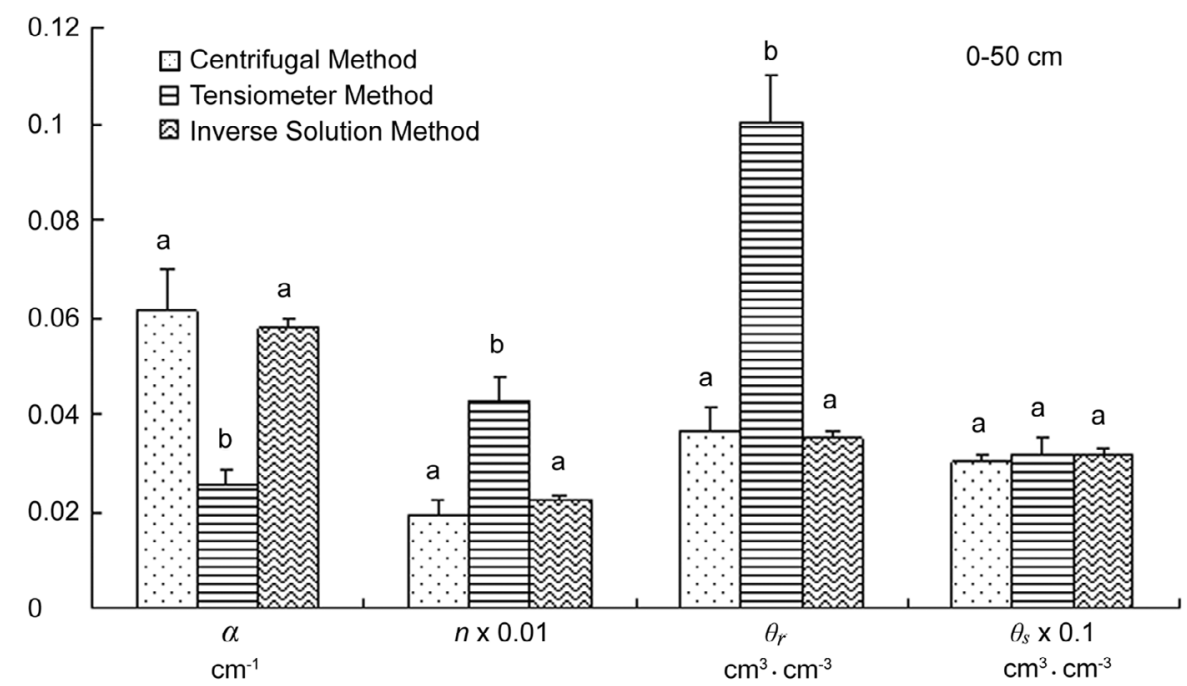

Fig. 3. Values of soil hydraulic parameters of the van Genuchten function above the depth of $50 \mathrm{~cm}$ by different methods. The characters above the columns indicate the significance. Columns with the same character do not show significant differences for $\mathrm{P}<0.05$.

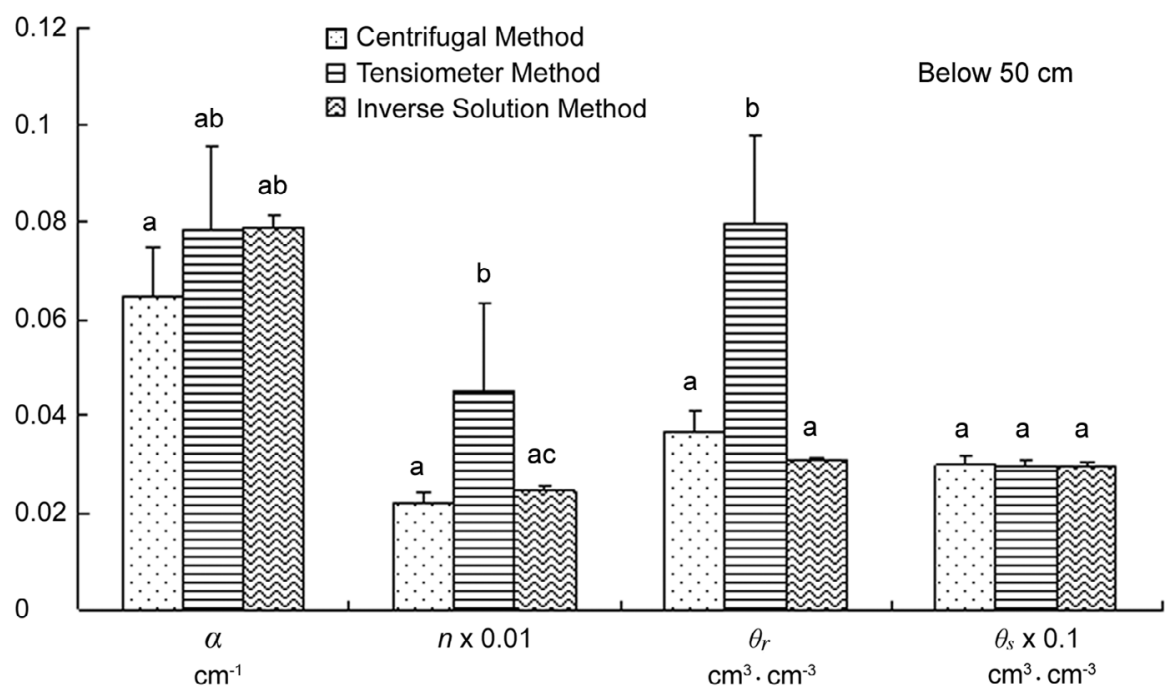

Fig. 4. Values of soil hydraulic parameters of the van Genuchten function below the depth of $50 \mathrm{~cm}$ by different methods. The characters above the columns indicate the significance. Columns with the same character do not show significant differences for $\mathrm{P}<0.05$. 
of Post Hoc Tests showed significant difference between TM and CM as well as between TM and ISM for $\alpha, n, \theta_{r}$ $(\mathrm{P}<0.001)$ in the $0-50 \mathrm{~cm}$ depth. Significant difference between TM and CM as well as between TM and ISM was only observed for $\theta_{r}(\mathrm{P}<0.001)$ and between TM and CM for $n(\mathrm{P}<0.001)$ below the depth of $50 \mathrm{~cm}$. Moreover, differences might exist but not reach a significant level $(\mathrm{P}<$ $0.01)$ between TM and $\mathrm{CM}$ for $\alpha(\mathrm{P}=0.042)$ and between TM and ISM for $n(\mathrm{P}=0.020)$ below the depth of $50 \mathrm{~cm}$.

All three measurement sets for each soil layer were pooled together for each van Genuchten parameter, and then Paired T Test was performed to explore the impact of soils on van Genuchten parameters between the $0-50 \mathrm{~cm}$ and below $50 \mathrm{~cm}$ layers. Table 4 also shows statistically results of van Genuchten function parameters of the two soil layers. Results showed significant differences for $\alpha, \theta_{r}, \theta_{s}(\mathrm{P}$ $<0.001)$ between the two layers. ANOVA analysis showed that a significant difference in $\alpha$ values for TM, ISM (P < $0.001)$, and in $\theta_{r}$ values for TM $(\mathrm{P}<0.001)$ between the two soil layers. Differences in $n$ for $\mathrm{CM}(\mathrm{P}=0.0305), \theta_{r}$ and $\theta_{s}$ for ISM $(\mathrm{P}=0.0317$ and 0.0350$)$ were also observed between the two soil layers.

\subsection{Soil Saturated Hydraulic Conductivity}

Values of soil saturated hydraulic conductivity $(K s)$ were obtained using the soil core method (SCM), disc infiltration method (DIM), and inverse solution method (ISM) in top $0-50 \mathrm{~cm}$ and below $50 \mathrm{~cm}$ as shown in Table 4 .

Table 4 shows that, the average values of $K s$ for DIM > ISM $>$ SCM in the top $0-50 \mathrm{~cm}$ and below $50 \mathrm{~cm}$. Moderate variation for $\mathrm{SCM}(\mathrm{CV}=24.7 \%, 19.5 \%)$, DIM $(\mathrm{CV}=$ $17.5 \%, 38.0 \%)$ and weak variation for ISM $(\mathrm{CV}=2.6 \%$, $3.4 \%$ ) were observed in the top $0-50 \mathrm{~cm}$ and below $50 \mathrm{~cm}$.
ANOVA analysis showed significant differences for $K s$ that were obtained using different methods $(\mathrm{P}<0.001)$ in both the top $0-50 \mathrm{~cm}$ and below $50 \mathrm{~cm}$ soil layers (Fig. 5). Results of Post Hoc Tests showed differences existed among all the three methods in the two layers, but the significant differences $(P=0.001)$ were observed between DIM and SCM in the top layer and between DIM and SCM as well as between DIM and ISM in the lower layer (Fig. 5). Comparing $K s$ values of soil layers between the $0-50 \mathrm{~cm}$ and below $50 \mathrm{~cm}$ layers, Paired T Test indicated significant differences for $K s$ between the two layers $(\mathrm{P}<0.001)$ (see Table 4). ANOVA analysis showed only significant difference for DIM and ISM $(\mathrm{P}<0.001)$ between the two layers.

\subsection{Analysis of Simulation Results}

Numerical simulations of the water flow were performed for obtaining hydraulic parameters that were obtained using different methods. Simulation results of different methods were compared with observed data as shown in Fig. 6. Visually, CM-DIM and TM-DIM overestimated the soil water infiltration process, while CM-SCM and TMSCM underestimated the infiltration process. Methods of DIM with higher $K s$ values have higher infiltration speed than the SCM methods, indicating that impact of $K s$ was more significant than other hydraulic parameters. Compared with other methods, ISM showed better simulating results, but it overestimates soil water content especially for the layer below the depth of $50 \mathrm{~cm}$. This may be caused by the high content of rock fragment in the whole soil profile, especially for the deeper layer. Without considering the impact of rock fragments in the HYDRUS-2D simulation, the vertical soil cross section was more uniform and assumed to be "sandy soil," which could hold more water than rock fragments in

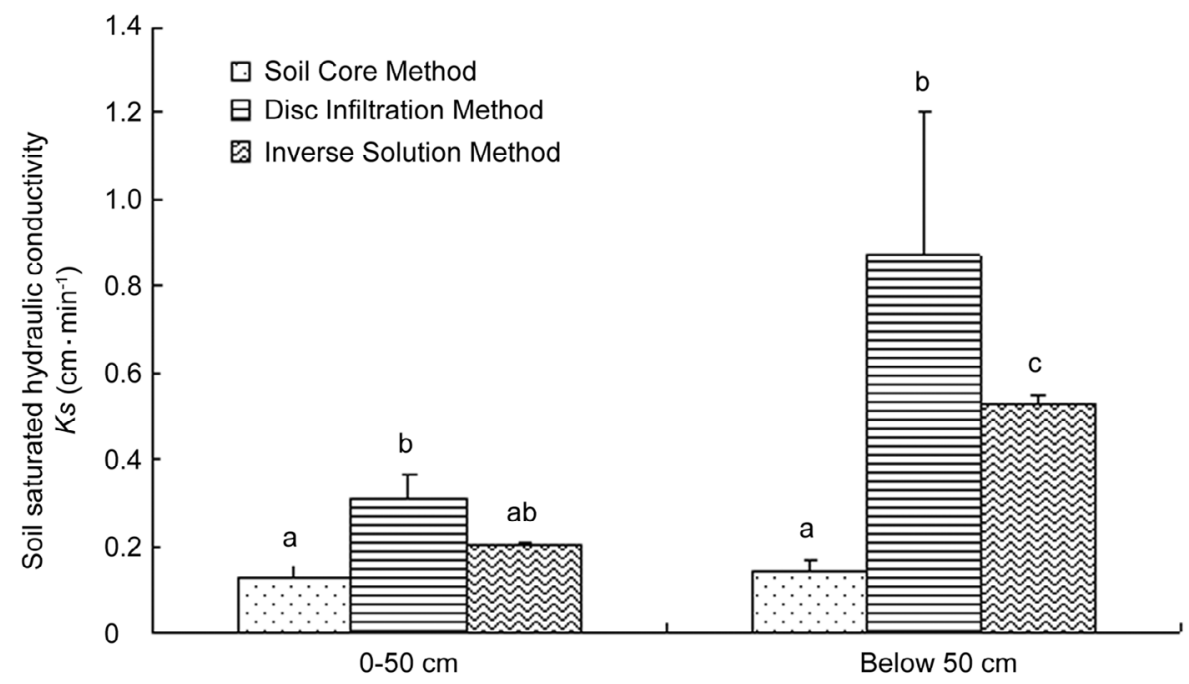

Fig. 5. Values of saturated soil hydraulic conductivities by different methods. The characters above the columns indicate the significance. Columns with the same character do not show significant differences for $\mathrm{P}<0.05$. 

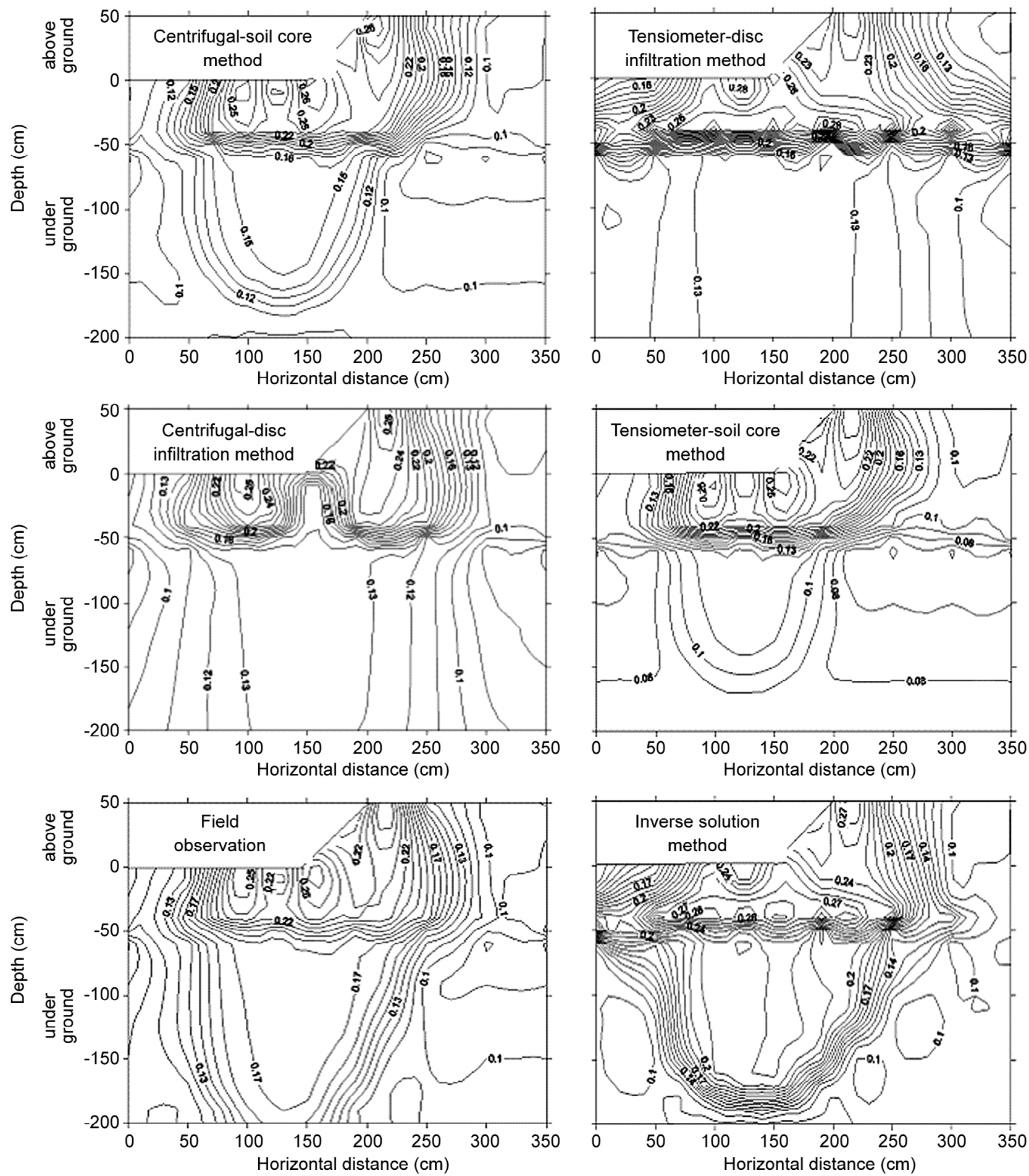

Fig. 6. The isoline graph of filed observed data and simulated results of soil water distribution in the vertical cross section.

the simulation process. Therefore, higher simulation values of soil water content were observed in the deeper layer.

Values of the simulation were compared to the observed data at the same location. Analytic results showed that (Table 5) the best simulation result with a higher correlation coefficient of 0.8369 for ISM, and 0.4068 for RESM. The relative error was less than $15 \%$. However, the CM-
SCM model produced the worst simulation result with a relative error of $50 \%$ and RMSE of 1.1336 .

\section{DISCUSSION AND CONCLUSIONS}

It is difficult to accurately and directly investigate soil hydraulic parameters in heterogeneous gravel soil. The 
Table 5. Statistical summary of soil water content for observed data verse different methods.

\begin{tabular}{cccccc}
\hline Source & $\mathbf{N}$ & Correlation & Sig. & Relative error & RMSE \\
\hline Observed data \& TM-DIM & 240 & 0.6619 & 0.0000 & $38.4 \%$ & 0.9829 \\
Observed data \& CM-DIM & 240 & 0.8052 & 0.0000 & $21.7 \%$ & 0.6367 \\
Observed data \& TM-SCM & 240 & 0.7942 & 0.0000 & $20.5 \%$ & 0.6369 \\
Observed data \& CM-SCM & 240 & 0.6652 & 0.0000 & $48.2 \%$ & 1.1336 \\
Observed data \& ISM & 240 & 0.8369 & 0.0000 & $14.3 \%$ & 0.4068 \\
\hline
\end{tabular}

Note: CM: centrifugal method; TM: tensiometer method; ISM: inverse solution method; SCM: soil core method; DIM: disc infiltrometer method.

HYDRUS-2D numerical simulation model was chosen in this study to evaluate the accuracy of hydraulic parameters that were indirectly measured using several methods.

The hydraulic parameters as obtained with the CM are significantly different from that obtained with the TM, so were from the CM and the ISM for $\alpha, n$, and $\theta_{r}$. The $K s$ parameter was significantly changed from the DIM to the SCM and from the DIM to the ISM. The hydraulic parameter of $\alpha$ by TM, ISM obtained in $0-50 \mathrm{~cm}$ soil layer are different from that obtained below $50 \mathrm{~cm}$, and were similar from the $0-50 \mathrm{~cm}$ and below $50 \mathrm{~cm}$ for $\theta_{r}$ and $K s$. The hydraulic parameters of $n$ by CM obtained in $0-50 \mathrm{~cm}$ soil layer are different from that obtained below $50 \mathrm{~cm}$ and the parameter of $\theta_{s}$ by DIM and ISM obtained are also different between the two layers. The simulation results of hydraulic parameters obtained using various methods showed that the ISM had a relatively smaller error (15\%) compared to other methods. The simulation results of parameters with the DIM were overestimated soil water infiltration process and results with the SCM were underestimated water mobility compared to the actual field results.

These analyses imply that the soil samples collected by the cutting ring sampler for the CM and SCM did not accurately reflect the impact of gravel on soil hydraulic parameters because the soil core cylinder was almost impossible to contain gravel due to the cutting ring size. Therefore, both CM and SCM yielded smaller Ks value than other methods and did not show difference between the two soil layers. In addition, the significant difference of $K s$ values as obtained with DIM, ISM and SCM was probably caused by two factors. First, the infiltration process measured by a disc infiltrometer could only reach a near-steady state under near-saturated condition rather than saturated condition. Second, the existence of rock fragments could easily lead to macro-pore flow and result in higher $K s$ values. The ISM yielded the best simulation results among all methods used in this study because the effect of gravel on the whole profile by a "black-box" scheme was taken into account. However, this method discounted the effect of rock fragments on soil water distribution especially in the deeper soil layer, hence the simulated soil water values were higher than the values actually observed in the deeper soil layer.
Acknowledgements The study was financially supported by the Ministry of Science and Technology of the People's Republic of China (MOST) for the Global Change Research Program 2010CB951702, by the Chinese Academy of Sciences (CAS) for the Knowledge Innovation Program KZCX2-EW-112, by the National Natural Science Foundation of China (41001034 and 51179150), by the CAS for the Hundred Talents Program and the National Key Technology Research and Development Program (2011BAD29B05).

\section{REFERENCES}

Ankeny, M. D., T. C. Kaspar, and R. Horton, 1988: Design for an automated tension infiltrometer. Soil Sci. Soc. Am.J., 52, 893-896, doi: 10.2136/sssaj1988.03615995 005200030054x. [Link]

Bagarello, V. and A. Sgroi, 2004: Using the single-ring infiltrometer method to detect temporal changes in surface soil field-saturated hydraulic conductivity. Soil Till. Res., 76, 13-24, doi: 10.1016/j.still.2003.08.008. [Link]

Bagarello, V. and A. Sgroi, 2007: Using the simplified falling head technique to detect temporal changes in fieldsaturated hydraulic conductivity at the surface of a sandy loam soil. Soil Till.Res., 94, 283-294, doi: 10.10 16/j.still.2006.08.001. [Link]

Bagarello, V., M. Castellini, and M. Iovino, 2005: Influence of the pressure head sequence on the soil hydraulic conductivity determined with tension infiltrometer. Appl. Eng. Agric., 21, 383-391.

Ben-Gal, A., N. Lazorovitch, and U. Shani, 2004: Subsurface drip irrigation in gravel-filled cavities. Vadose Zone J., 3, 1407-1413, doi: 10.2136/vzj2004.1407. [Link]

Bouwer, H. and R. C. Rice, 1984: Hydraulic properties of stony vadose zones. Ground Water, 22, 696-705, doi: 10.1111/j.1745-6584.1984.tb01438.x. [Link]

Brakensiek, D. L., W. J. Rawls, and G. R. Stephenson, 1986: Determining the saturated hydraulic conductivity of a soil containing rock fragments. Soil Sci. Soc. Am. J., 50, 834-835, doi: 10.2136/sssaj1986.03615995005000 030053x. [Link] 
Brunone, B., M. Ferrante, N. Romano, and A. Santini, 2003: Numerical simulations of one-dimensional infiltration into layered soils with the Richards equation using different estimates of the interlayer conductivity. Vadose Zone J., 2, 193-200, doi: 10.2136/vzj2003.0193. [Link]

Chu, S. T., 1994: Green-Ampt analysis of wetting patterns for surface emitters. J. Irrig. Drain. Eng., 120, 414421, doi: 10.1061/(ASCE)0733-9437(1994)120:2(414). [Link]

Cote, C. M., K. L. Bristow, P. B. Charlesworth, F. J. Cook, and P. J. Thorburn, 2003: Analysis of soil wetting and solute transport in subsurface trickle irrigation. Irrig. Sci., 22, 143-156, doi: 10.1007/s00271-003-0080-8. [Link]

Das Gupta, S., B. P. Mohanty, and J. M. Köhne, 2006: Soil hydraulic conductivities and their spatial and temporal variations in a vertisol. Soil Sci. Soc. Am. J., 70, 18721881, doi: 10.2136/sssaj2006.0201. [Link]

Elmaloglou, S. and E. Diamantopoulos, 2008: The effect of intermittent water application by surface point sources on the soil moisture dynamics and on deep percolation under the root zone. Comput. Electron. Agric., 62, 266275, doi: 10.1016/j.compag.2008.01.008. [Link]

Elrick, D. E. and W. D. Reynolds, 1992: Methods for analyzing constant-head well permeameter data. Soil Sci. Soc. Am. J., 56, 320-323, doi: 10.2136/sssaj1992.0361 5995005600010052x. [Link]

EriKsson, C. P. and P. Holmgren, 1996: Estimating stone and boulder content in forest soils - Evaluating the potential of surface penetration methods. Catena, 28, 121-134, doi: 10.1016/S0341-8162(96)00031-8. [Link]

Flint, A. L. and S. Childs, 1984: Physical properties of rock fragments and their effect on available water in skeletal soils. In: Nichols, J. D., P. L. Brown, and W. J. Grant (Eds.), Erosion and Productivity of Soils Containing Rock Fragments, SSSA Special Publication, No. 13, Madison, WI. 91-103.

Fleming, R. L., T. A. Black and, N. R. Eldridge, 1993: Water content, bulk density, and coarse fragment content measurement in forest soils. Soil Sci. Soc. Am. J., 57, 261-270, doi: 10.2136/sssaj1993.03615995005700010 045x. [Link]

Gärdenäs, A. I., J. W. Hopmans, B. R. Hanson, and J. Šimůnek, 2005: Two-dimensional modeling of nitrate leaching for various fertigation scenarios under microirrigation. Agric. Water Manage., 74, 219-242, doi: 10. 1016/j.agwat.2004.11.011. [Link]

Hu, W., M. Shao, Q. Wang, J. Fan, and R. Horton, 2009: Temporal changes of soil hydraulic properties under different land uses. Geoderma, 149, 355-366, doi: 10. 1016/j.geoderma.2008.12.016. [Link]

Khaleel, R. and P. R. Heller, 2003: On the hydraulic properties of coarse-textured sediments at intermediate water contents. Water Resour. Res., 39, 1029-1233, doi: 10.
1029/2003WR002387. [Link]

Klute, A. and C. DirKsen, 1986: Hydraulic conductivity and diffusivity: Laboratory methods. In: Klute, A. (Ed.), Methods of Soil Analysis: Part I - Physical and Minerological Methods: Soil Science Society of America Book Series No. 5, Soil Science Society of America, Madison, Wisconsin, 687-734.

Lei, Z. D., S. Yang, and S. Xie, 1988: Soil Water Dynamics. Tsinghua University Press, Beijing, 30-55.

Logsdon, S. D. and D. B. Jaynes, 1993: Methodology for determining hydraulic conductivity with tension infiltrometers. Soil Sci. Soc. Am. J., 57, 1426-1431, doi: 10.2136/sssaj1993.03615995005700060005x. [Link]

Lubana, P.P. S. and N. K. Narda, 2001: SW - Soil and Water: Modelling Soil Water Dynamics under Trickle Emitters - A Review. J. Agric. Eng. Res., 78, 217-232, doi: 10.1006/jaer.2000.0650. [Link]

Ma, D., Q. Wang, and M. Shao, 2009: Analytical method for estimating soil hydraulic parameters from horizontal absorption. Soil Sci. Soc. Am. J., 73, 727-736, doi: 10.2136/sssaj2008.0050. [Link]

Ma, D., M. Shao, J. Zhang and Q. Wang, 2010: Validation of an analytical method for determining soil hydraulic properties of stony soils using experimental data. Geoderma, 159, 262-269, doi: 10.1016/j.geoderma.2010. 08.001. [Link]

Mehuys, G. R., L. H. Stolzy, J. Letey, and L. V. WeeKs, 1975: Effect of stones on the hydraulic conductivity of relatively dry desert soils. Soil Sci. Soc. Am. J., 39, 37-42, doi: 10.2136/sssaj1975.0361599500390001001 3x. [Link]

Messing, I. and N. J. Jarvis, 1990: Seasonal variation in fieldsaturated hydraulic conductivity in two swelling clay soils in Sweden. Eur. J. Soil Sci., 41, 229-237, doi: 10. 1111/j.1365-2389.1990.tb00059.x. [Link]

Mualem, Y., 1976: A new model for predicting the hydraulic conductivity of unsaturated porous media. Water Resour. Res., 12, 513-522, doi: 10.1029/WR012i003p 00513. [Link]

Muller, R. N. and M. E. Hamilton, 1992: A simple, effective method for determining the bulk density of stony soils. Commun. Soil Sci. Plant Anal., 23, 313-319, doi: 10.1080/00103629209368590. [Link]

Pachepsky, Y., D. Timlin, and W. Rawls, 2003: Generalized Richards's equation to simulate water transport in unsaturated soils. J. Hydrol., 272, 3-13, doi: 10.1016/S0 022-1694(02)00251-2. [Link]

Perroux, K. M. and I. White, 1988: Designs for disc permeameters. Soil Sci. Soc. Am. J., 52, 1205-1215, doi: 10.2136/sssaj1988.03615995005200050001x. [Link]

Provenzano, G., 2007: Using HYDRUS-2D simulation model to evaluate wetted soil volume in subsurface drip irrigation systems. J. Irrig. Drain. Eng., 133, 342-349, doi: 10.1061/(ASCE)0733-9437(2007)133:4(342). [Link] 
Ravina, I. and J. Magier, 1984: Hydraulic conductivity and water retention of clay soils containing coarse fragments. Soil Sci. Soc. Am. J., 48, 736-740, doi: 10.2136/ sssaj1984.03615995004800040008x. [Link]

Reeve, M. J., D. G. M. Hall, and P. Bullock, 1980: The effect of soil composition and environmental factors on the shrinkage of some clayey British soils. Eur. J. Soil Sci., 31, 429-442, doi: 10.1111/j.1365-2389.1980.tb02 092.x. [Link]

Rey, E., D. Jongmans, P. Gotteland, and S. Garambois, 2006: Characterisation of soils with stony inclusions using geoelectrical measurements. J. Appl. Geophys., 58, 188-201, doi: 10.1016/j.jappgeo.2005.06.003. [Link]

Reynolds, W.D. and D.E.Elrick, 1985: In situ measurement of field-saturated hydraulic conductivity, sorptivity, and the $\alpha$-parameter using the Guelph permeameter. Soil Sci., 140, 292-302, doi: 10.1097/00010694-198510000 -00008. [Link]

Sauer, T. J. and S. D. Logsdon, 2002: Hydraulic and physical properties of stony soils in a small watershed. Soil Sci. Soc. Am. J., 66, 1947-1956, doi: 10.2136/sssaj20 02.1947. [Link]

Šimůnek, J., M. Šejna, and M. Th. van Genuchten, 1999: The HYDRUS-2D software package for simulating two-dimensional movement of water, heat and multiple solutes in variably saturated media. Version 2.0, US Salinity Laboratory, Agricultural Research Service, US Department of Agriculture, Riverside California, 11-73.

Skaggs, T. H., T. J. Trout, J. Šimůnek, and P. J. Shouse, 2004: Comparison of HYDRUS-2D simulations of drip irrigation with experimental observations. J. Irrig . Drain. Eng., 130, 304-310, doi: 10.1061/(ASCE)073 3-9437(2004)130:4(304). [Link]

Starr, J. L., 1990: Spatial and temporal variation of ponded infiltration. Soil Sci. Soc. Am. J., 54, 629-636, doi: 10.2136/sssaj1990.03615995005400030001x. [Link]

van Es, H. M., C. B. Ogden, R. L. Hill, R. R. Schindelbeck, and T. Tsegaye, 1999: Integrated assessment of space, time, and management-related variability of soil hydraulic properties. Soil Sci.Soc. Am. J., 63, 1599-1608, doi: 10.2136/sssaj1999.6361599x. [Link]

van Genuchten, M. Th., 1980: A closed-form equation for predicting the hydraulic conductivity of unsaturated soils. Soil Sci. Soc. Am. J., 44, 892-898, doi: 10.2136/ sssa1980.03615995004400050002x. [Link]

van Genuchten, M. Th., F. J. Leij, and S. R. Yates, 1991: The RETC code for quantifying the hydraulic functions of unsaturated soils. US Salinity Laboratory, US Department of Agriculture, Agricultural Research Service, Riverside, California.

Ventrella, D., N. Losavio, A. V. Vonella, and F. J. Leij, 2005: Estimating hydraulic conductivity of a fine-textured soil using tension infiltrometry. Geoderma, 124, 267-277, doi: 10.1016/j.geoderma.2004.05.005. [Link]

Viro, P. J., 1952. On the determination of stoniness, Summary. Comm. Inst. Forest. Fenn., 40, 1-19.

$\mathrm{Xu}$, D. and A. Mermoud, 2003: Modeling the soil water balance based on time-dependent hydraulic conductivity under different tillage practices. Agric. Water Manage., 63, 139-151, doi: 10.1016/S0378-3774(03)00180-x. [Link] 